\title{
Impact of COVID-19 on gastroenterology fellowship training: a multicenter analysis of endoscopy volumes
}

\section{(ㄷ)(1) $\odot$}

\section{Authors}

Swathi Paleti ${ }^{*}, 1$, Zain A. Sobani ${ }^{*}, 1$, Thomas R. McCarty², Aditya Gutta ${ }^{3}$, Anas Gremida ${ }^{4}$ Raj Shah ${ }^{5}$, Venkat Nutalapati ${ }^{6}$, Fateh Bazerbachi ${ }^{7}$, Randhir Jesudoss ${ }^{8}$, Shreya Amin ${ }^{9}$, Chinemerem Okwara ${ }^{9}$, Pradeep Reddy Kathi ${ }^{10}$, Ali Ahmed ${ }^{11}$, Luke Gessel ${ }^{12}$, Kenneth Hung ${ }^{13}$, Amir Masoud ${ }^{13}$, Jessica Yu ${ }^{14}$, Shruti Mony ${ }^{15}$, Venkata Akshintala ${ }^{15}$, Laith Jamil $^{16}$, Thayer Nasereddin ${ }^{17}$, Gursimran Kochhar ${ }^{17}$, Neil Vyas ${ }^{18}$, Shreyas Saligram ${ }^{18}$, Rajat Garg ${ }^{19}$, Dalbir Sandhu ${ }^{19}$, Karim Benrajab ${ }^{20}$, Rajesh Konjeti ${ }^{20}$, Abhishek Agnihotri ${ }^{21}$, Hirsh Trivedi ${ }^{21}$, Matthew Grunwald ${ }^{22}$, Ira Mayer ${ }^{22}$, Arpan Mohanty ${ }^{23}$, Tarun Rustagi ${ }^{1}$

\section{Institutions}

1 Division of Gastroenterology and Hepatology University of New Mexico, Albuquerque, NM

2 Division of Gastroenterology, Hepatology and Endoscopy, Brigham and Women's Hospital, Harvard Medical School. Boston, Massachusetts, United States

3 Division of Gastroenterology and Hepatology, Indiana University School of Medicine, Indianapolis, Indiana, United States

4 Division of Gastroenterology and Hepatology, Washington University School of Medicine, St Louis, Missouri, United States

5 Division of Gastroenterology and Hepatology, Case Western Reserve University School of Medicine, Cleveland, Ohio, United States

6 Division of Gastroenterology and Hepatology, University of Kansas Medical Center, Kansas City, Kansas, United States

7 Division of Gastroenterology and Hepatology, Massachusetts General Hospital, Boston, Massachusetts, United States

8 Division of Gastroenterology and Hepatology, University of lowa, lowa City, Iowa, United States

9 Division of Gastroenterology and Hepatology, University of Texas Southwestern Medical Center, Dallas, Texas, United States

10 Division of Gastroenterology and Hepatology, University of Arizona School of Medicine, Tuscon, Arizona, United States

11 Division of Gastroenterology and Hepatology, University of Alabama at Birmingham School of Medicine, Birmingham, Alabama, United States

12 Division of Gastroenterology and Hepatology, University of Utah, Salt Lake City, Utah, United States

13 Division of Gastroenterology and Hepatology, Yale School of Medicine, New Haven, Connecticut, United States
14 Division of Gastroenterology and Hepatology, Oregon Health \& Science University, Portland, Oregon, United States

15 Division of Gastroenterology and Hepatology, The Johns Hopkins University School of Medicine, Baltimore, Maryland, United States

16 Division of Gastroenterology and Hepatology, Oakland University William Beaumont School of Medicine, Royal Oak, Michigan, United States

17 Division of Gastroenterology and Hepatology, Allegheny Health Network, Pittsburgh, Pennsylvania, United States

18 Division of Gastroenterology and Hepatology, University of Texas Health Science Center at San Antonio, San Antonio, Texas, United States

19 Division of Gastroenterology and Hepatology, Cleveland Clinic Foundation, Cleveland, Ohio, United States

20 Division of Gastroenterology and Hepatology, University of Kentucky, Lexington, Kentucky, United States

21 Division of Gastroenterology and Hepatology, Beth Israel Deaconess Medical Center, Harvard Medical School, Boston, Massachusetts, United States

22 Division of Gastroenterology and Hepatology, Maimonides Medical Center, New York, New York, United States

23 Division of Gastroenterology and Hepatology, Boston University School of Medicine, Boston, Massachusetts, United States

submitted 16.4.2021

accepted after revision $\quad 19.5 .2021$

Bibliography

Endosc Int Open 2021; 09: E1572-E1578

DOI 10.1055/a-1526-1419

ISSN 2364-3722

(c) 2021. The Author(s).

\footnotetext{
* These authors contributed equally.
} 
This is an open access article published by Thieme under the terms of the Creative Commons Attribution-NonDerivative-NonCommercial License, permitting copying and reproduction so long as the original work is given appropriate credit. Contents may not be used for commercial purposes, or adapted, remixed, transformed or built upon. (https://creativecommons.org/licenses/by-nc-nd/4.0/)

Georg Thieme Verlag KG, Rüdigerstraße 14,

70469 Stuttgart, Germany

Corresponding author

Tarun Rustagi, MD, Division of Gastroenterology and Hepatology, University of New Mexico School of Medicine, 1 University of New Mexico, MSC10-5550, Albuquerque, NM 87131, USA

Fax: +1- 505-272-6839

tarunrustagi06@gmail.com

\section{ABSTRACT}

Background and study aims The COVID-19 pandemic has had a profound impact on gastroenterology training programs. We aimed to objectively evaluate procedural training volume and impact of COVID-19 on gastroenterology fellowship programs in the United States.

Methods This was a retrospective, multicenter study. Procedure volume data on upper and lower endoscopies performed by gastroenterology fellows was abstracted directly from the electronic medical record. The study period was stratified into 2 time periods: Study Period 1, SP1 (03/15/ 2020 to 06/30/2020) and Study Period 2, SP2 (07/01/2020 to $12 / 15 / 2020)$. Procedure volumes during SP1 and SP2 were compared to Historic Period 1 (HP1) (03/15/2019 to 06/30/2019) and Historic Period 2 (HP2) (07/01/2019 to $12 / 15 / 2019)$ as historical reference.

Results Data from 23 gastroenterology fellowship programs (total procedures $=127,958$ ) with a median of 284 fellows (range 273-289; representing $17.8 \%$ of all trainees in the United States) were collected. Compared to HP1, fellows performed $53.6 \%$ less procedures in SP1 (total volume: 28,808 vs 13,378 ; mean $105.52 \pm 71.94$ vs $47.61 \pm 41.43$ per fellow; $P<0.0001)$. This reduction was significant across all three training years and for both lower and upper endoscopies $(P<0.0001)$. However, the reduction in volume was more pronounced for lower endoscopy compared to upper endoscopy [59.03\% (95\% Cl: $58.2-59.86)$ vs $48.75 \%$ (95\% $\mathrm{Cl}: 47.96-49.54) ; P<0.0001]$. The procedure volume in SP2 returned to near baseline of HP2 (total volume: 42,497 vs 43,275 ; mean $147.05 \pm 96.36$ vs $150.78 \pm 99.67 ; P=$ $0.65)$.

Conclusions Although there was a significant reduction in fellows' endoscopy volume in the initial stages of the pandemic, adaptive mechanisms have resulted in a return of procedure volume to near baseline without ongoing impact on endoscopy training.

\section{Introduction}

The coronavirus disease (COVID-19) outbreak, first identified in December 2019, has become a global pandemic, resulting in approximately 92 million cases and 1.9 million deaths worldwide [1]. The United States has been one of the most severely affected nations, recording over 23 million cases and 380,000 deaths - becoming the epicenter of the SARS-CoV-2 (2019$\mathrm{nCoV}$ ) infection. Along with this devastating impact to patients and immense burden on healthcare systems, the COVID-19 pandemic has caused an unprecedented disruption in medical education and physician training [2,3]. Multiple healthcare centers, both university and community programs, have reduced the volume of elective visits, procedures, and even redeployed trainees to other critical services to meet the demands of the COVID-19 pandemic.

While these extraordinary times have impacted all facets of medical education and training, training in surgical and procedural specialties such as gastroenterology which require residents and fellows to achieve procedural competencies, have been uniquely affected. Changes to fellowship rotations, inpatient consult services, outpatient clinics, and reduction in endoscopy hours (or in some cases, complete closure of units) have aimed to reduce elective cases, promote a culture of safety, but also limited clinical exposure for gastroenterology fellows [4-7]. In response to COVID-19, the Accreditation Council for
Graduate Medical Education (ACGME) made a statement that “The visits/Case Logs of a program's graduates who were on duty during this pandemic (particularly those in their ultimate or penultimate years) will be judiciously evaluated in light of the impact of the pandemic on that program" [8]. Yet, despite this acknowledgement by the ACGME, some studies have shown a correlation between procedural volumes and acquisition of skills and patient related outcomes [9-12].

Large-scale assessment of COVID-19 and its impact on gastroenterology fellowship training is currently limited to survey results and opinion pieces $[4-6,13]$. One single-center study during the COVID-19 pandemic did demonstrate an overall 50 $\%$ reduction in the number of inpatient upper endoscopies performed among trainee providers [14]. Other subjective studies with self-reported data have shown that $93.8 \%$ of a cohort of 770 trainees worldwide reported a reduction in their monthly procedure volumes, with colonoscopies reduced more than other procedures [15]. A survey of 177 gastroenterology fellows, all within the United States, demonstrated that COVID19 impacted all aspects of training, including endoscopy, outpatient clinics, inpatient consults, and educational activities [13]. While these data were critical to evaluate the impact of COVID-19 on gastroenterology fellowship training, the vast majority of published literature reports outcomes or survey responses early on in the pandemic, and does not allow for objective measurements to evaluate changes in procedural volume, 
or assess fellowship programs' ability to respond to the current pandemic.

Given that the pandemic has been ongoing for the last 10 months, serious concerns have been raised about its impact on trainees as it encompasses roughly $25 \%$ of the 3 -year fellowship training period; however, objective data are lacking. The aim of this study was to audit gastroenterology fellowship programs across the United States to objectively evaluate the impact of COVID-19 on fellows' endoscopy volume prior to implementing strategies to address these perceived issues in fellowship training.

\section{Methods}

This was a multicenter, retrospective study of ACGME-accredited gastroenterology fellowship training programs across the United States, which aimed to investigate the volume of endoscopic procedures performed by fellow trainees. Participating programs extracted deidentified aggregate procedural data from their electronic medical records (EMR) or electronic endoscopy reporting system (EERS) (eg. ProVation MD, ProVation Medical, Inc, Minneapolis, Minnesota, United States; MDReports Infinite Software Solutions, Inc., Staten Island, New York, United States; and EndoWorks Olympus America, Inc Center Valley, Pennsylvania, United States) including the number of endoscopic procedures performed during the pre-specified time periods. These procedures were performed by gastroenterology fellows under the direct supervision of attending physicians. The study period was stratified into two time periods to adjust for the transition to the new academic year on July 1 , 2020 (i.e March 15, 2020 to June 30, 2020 (Study Period 1, SP1) and July 1, 2020 to December 15, 2020 (Study Period 2, SP2). A comparison was performed with the same time period in the year prior, which served a historical cohort for reference or comparison purposes (i. e. March 15, 2019 to June 30, 2019 (Historic Period 1, HP1) and July 1, 2019 to December 15, 2019 (Historic Period 2, HP2).

Endoscopic procedures were divided into upper gastrointestinal endoscopy (esophagogastroduodenoscopy and push enteroscopy) and lower gastrointestinal endoscopy (flexible sigmoidoscopy and colonoscopy). Other endoscopic procedures including antegrade or retrograde balloon (device)-assisted enteroscopy, endoscopic ultrasound, and endoscopic retrograde cholangiopancreatography were excluded as most of these are performed by advanced endoscopy trainees at most participating institutions and may lead to a lack of generalizability. Data were strictly extracted from the EMR and/or EERS to avoid subjective and reporting biases. Detailed data harvesting instructions were provided to all participating sites along with access to point of contact from the primary investigators to resolve any issues or concerns with data collection. Data were not considered from trainee self-reported logs and centers that could not provide direct data were excluded. Programs were encouraged to include data from all their training sites; however, if regulatory or logistic barriers prevented the inclusion of all training sites, data from primary training sites were considered.
Statistical analysis was performed by using Student's t-test for comparing means and standard deviations for continuous variables. Percentage change in endoscopy volumes with $95 \%$ confidence intervals were calculated and compared for statistical significance among different time periods. $P \leq 0.05$ was considered statistically significant. The study received a waiver from institutional review board at University of New Mexico given the collection of deidentified aggregate data.

\section{Results}

Data were collected from 23 gastroenterology fellowship programs with a total of 127,958 procedures performed by the fellows. Program sizes ranged from two to eight fellows per year. Given that data collection spanned different academic periods, there was minor variation in the number of fellows between the study time periods. There were a median of 284 fellows (range 273-289) in each time period.

\section{Comparing SP1 (3/15/2020 to 6/30/2020) to HP1 (3/15/2019 to $6 / 30 / 2019)$}

The total number of procedures performed by fellows were markedly reduced by $53.6 \%(95 \% \mathrm{Cl}: 52.98-54.14)$ from 28,808 in HP1 to 13,378 in SP1. There was significant reduction in mean total volume $(105.52 \pm 71.94$ vs $47.61 \pm 41.43 ; P<$ $0.0001)$, mean upper endoscopies $(56.15 \pm 38.67$ vs $27.95 \pm$ 24.26; $P<0.0001)$, and mean lower endoscopies $(49.38 \pm 38.38$ vs $19.65 \pm 20.06 P<0.0001)$ per fellow between HP1 and SP1, respectively ( $\triangleright$ Fig. $\mathbf{1}, \triangleright$ Table $\mathbf{1}, \triangleright$ Table $\mathbf{2}$ ). The reduction in volume was more pronounced for lower endoscopy compared to upper endoscopy (59.03\% [95\% Cl: $58.2-59.86$ ] vs $48.75 \%$ [95\% Cl: 47.96-49.54]; $P<0.0001)$.

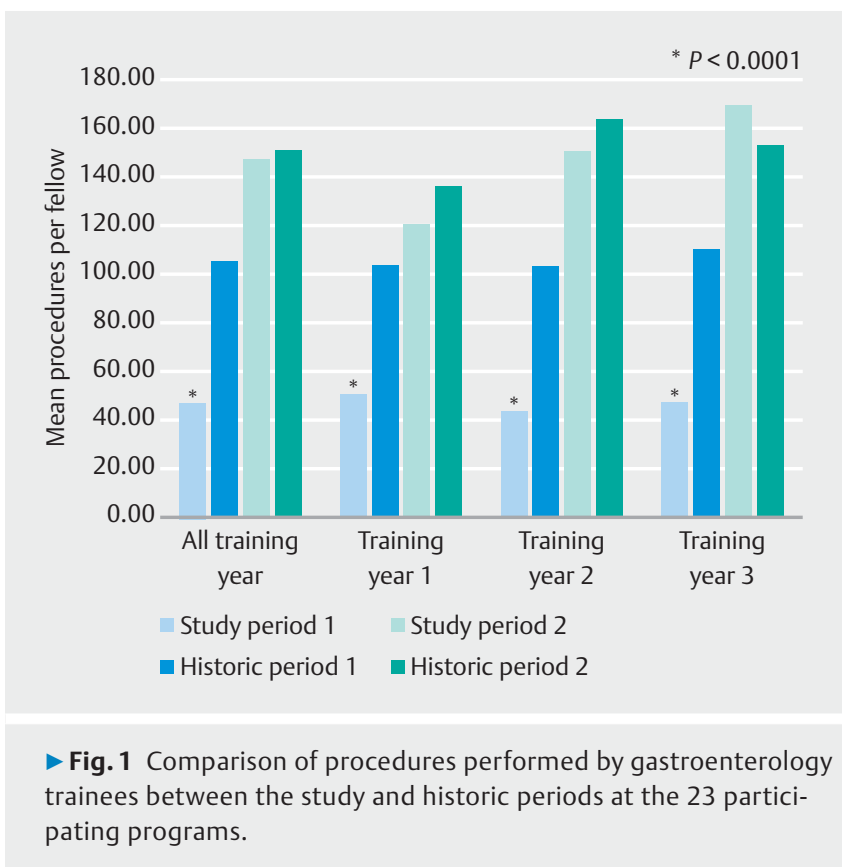


- Table 1 Summary of upper endoscopies performed by gastroenterology trainees at the 23 participating programs.

\begin{tabular}{|c|c|c|c|c|c|c|c|c|}
\hline & $\begin{array}{l}\text { Study } \\
\text { period } 1\end{array}$ & $\begin{array}{l}\text { Historic } \\
\text { period } 1\end{array}$ & $\%$ reduction & $P$ value & $\begin{array}{l}\text { Study } \\
\text { period } 2\end{array}$ & $\begin{array}{l}\text { Historic } \\
\text { period } 2\end{array}$ & $\%$ reduction & $P$ value \\
\hline \multicolumn{9}{|l|}{ Training year 1} \\
\hline Number of fellows ( $\mathrm{n}$ ) & 93 & 95 & & & 96 & 94 & & \\
\hline No. of procedures & 3038 & 5964 & $\begin{array}{l}49.06 \\
(47.79-50.33)\end{array}$ & & 7399 & 7997 & $7.48(6.92-8.08)$ & \\
\hline Mean procedures & $32.67 \pm 25.75$ & $62.78 \pm 35.65$ & & $<0.0001$ & $77.07 \pm 50.16$ & $85.07 \pm 54.17$ & & 0.2921 \\
\hline \multicolumn{9}{|l|}{ Training year 2} \\
\hline Number of fellows ( $\mathrm{n}$ ) & 95 & 93 & & & 94 & 98 & & \\
\hline No. of procedures & 2390 & 4879 & $\begin{array}{l}51.01 \\
(49.61-52.41)\end{array}$ & & 7214 & 7983 & $9.63(9.0-10.3)$ & \\
\hline Mean procedures & $25.16 \pm 20.23$ & $52.46 \pm 37.77$ & & $<0.0001$ & $76.74 \pm 50.91$ & $81.46 \pm 56.22$ & & 0.5433 \\
\hline \multicolumn{9}{|l|}{ Training year 3} \\
\hline Number of fellows ( $\mathrm{n}$ ) & 93 & 85 & & & 99 & 95 & & \\
\hline No. of procedures & 2427 & 4485 & $\begin{array}{l}45.89 \\
(44.44-47.35)\end{array}$ & & 8062 & 7182 & $\begin{array}{l}\text { Increase } 12.25 \\
(11.51-13.04)\end{array}$ & \\
\hline Mean procedures & $26.1 \pm 26.01$ & $52.76 \pm 42.2$ & & $<0.0001$ & $81.43 \pm 52.43$ & $75.6 \pm 54.86$ & & 0.4501 \\
\hline \multicolumn{9}{|l|}{ All training years } \\
\hline Number of fellows (n) & 281 & 273 & & & 289 & 287 & & \\
\hline No. of procedures & 7855 & 15328 & $\begin{array}{l}48.75 \\
(47.96-49.54)\end{array}$ & & 22675 & 23162 & $2.10(1.92-2.29)$ & \\
\hline Mean procedures & $27.95 \pm 24.26$ & $56.15 \pm 38.67$ & & $<0.0001$ & $78.46 \pm 51.06$ & $80.7 \pm 55.05$ & & 0.6128 \\
\hline
\end{tabular}

\section{Comparing SP2 (7/1/2020 to $12 / 15 / 2020)$ to HP2 (7/1/2019 to $12 / 15 / 2019)$}

The total number of procedures performed by fellows were marginally reduced by $1.8 \%$ (95\% Cl: 1.68-1.93) from 43,275 in HP2 to 42,497 in SP2. There was no difference in mean total volume (150.78 \pm 99.67 vs $147.05 \pm 96.36 ; P=0.6481)$, mean upper endoscopies ( $80.70 \pm 55.05$ vs $78.46 \pm 51.46 ; P=0.6128)$, and mean lower endoscopies $(70.08 \pm 53.63$ vs $68.59 \pm 54.16 ; P=$ 0.7402 ) per fellow between HP2 and SP2, respectively ( $\triangleright$ Fig. 1 , - Table 1, - Table 2 ). The reduction in volume was more pronounced for upper endoscopy compared to lower endoscopy (2.10\% [95\% Cl: 1.92-2.29] vs $1.45 \%$ [95\% Cl: 1.29-1.62]; $P<$ $0.05)$.

\section{Subgroup analysis}

Subgroup analysis between different training years showed significant reduction in total procedure volume, upper endoscopies, and lower endoscopies across all three training years during SP1 compared to HP1 $(P<0.0001)$ ( $>$ Table $1, \triangleright$ Table 2$)$. Fellows in training year 1 had the least reduction in lower endoscopies and fellows in training year 3 had significantly less reduction in upper endoscopy volume, compared to fellows in other training years $(P<0.05)(\vee$ Table $\mathbf{1}$, $>$ Table 2 ).

There was no significant difference across all three training years for total procedure volume, upper endoscopies, and low- er endoscopies between SP2 and HP2 $(P>0.05)$ ( $\triangleright$ Table 1 , - Table 2). Although not significant, fellows in training year 3 were found to have an increase in total procedure volume, upper endoscopies, and lower endoscopies, compared to a reduction in these volumes for fellows in training years 1 and 2 .

\section{Discussion}

Since March 2020, gastroenterology practices across the country have faced immense challenges due to the COVID-19 pandemic as institutions adapt to regulations on elective and semi-elective procedures from local and state governments, implement new standard operating procedures, and design infection control protocols. In addition, there has been a diversion of resources and manpower including physicians, nurses, and patient care technicians toward critical care areas. In a national survey of 177 gastroenterology trainees, $29.4 \%$ reported being redeployed to non-gastroenterology services during the pandemic [13]. Trainees in this survey felt the pandemic impacted multiple domains of their educational experience, including endoscopy. A majority (64.3\%) of the trainees believed that the pandemic would impact their endoscopic skills at the end of their training. Their concern regarding achieving competence in endoscopic skills was also echoed by international trainees [15]. While didactic training has managed to easily evolve onto multiple online platforms providing on-demand and interactive webinars, as well as structured social media education pro- 
- Table 2 Summary of lower endoscopies performed by gastroenterology trainees at the 23 participating programs.

\begin{tabular}{|c|c|c|c|c|c|c|c|c|}
\hline & $\begin{array}{l}\text { Study } \\
\text { period } 1\end{array}$ & $\begin{array}{l}\text { Historic } \\
\text { period } 1\end{array}$ & $\%$ reduction & $P$ value & $\begin{array}{l}\text { Study } \\
\text { period } 2\end{array}$ & $\begin{array}{l}\text { Historic } \\
\text { period } 2\end{array}$ & $\%$ reduction & $P$ value \\
\hline \multicolumn{9}{|l|}{ Training year 1} \\
\hline Number of fellows ( $\mathrm{n}$ ) & 93 & 95 & & & 96 & 94 & & \\
\hline No. of procedures & 1722 & 3892 & $\begin{array}{l}55.76 \\
(54.19-57.31)\end{array}$ & & 4187 & 4794 & $\begin{array}{l}12.66(11.75- \\
13.63)\end{array}$ & \\
\hline Mean procedures & $18.52 \pm 15.39$ & $40.97 \pm 28.52$ & & $<0.0001$ & $43.61 \pm 30.16$ & $51 \pm 30.92$ & & 0.0970 \\
\hline \multicolumn{9}{|l|}{ Training year 2} \\
\hline Number of fellows ( $n$ ) & 95 & 93 & & & 94 & 98 & & \\
\hline No. of procedures & 1820 & 4723 & $\begin{array}{l}61.47 \\
(60.07-62.85)\end{array}$ & & 6922 & 8020 & $\begin{array}{l}13.69(12.96- \\
14.46)\end{array}$ & \\
\hline Mean procedures & $19.16 \pm 20.86$ & $50.78 \pm 40.4$ & & $<0.0001$ & $73.64 \pm 54.76$ & $81.84 \pm 61.02$ & & 0.3290 \\
\hline \multicolumn{9}{|l|}{ Training year 3} \\
\hline Number of fellows ( $n$ ) & 93 & 85 & & & 99 & 95 & & \\
\hline No. of procedures & 1981 & 4865 & $\begin{array}{l}59.28 \\
(57.89-60.65)\end{array}$ & & 8713 & 7299 & $\begin{array}{l}\text { Increase } 19.37 \\
(18.48-20.29)\end{array}$ & \\
\hline Mean procedures & $21.3 \pm 23.21$ & $57.24 \pm 43.89$ & & $<0.0001$ & $88.01 \pm 62.26$ & $76.83 \pm 58.38$ & & 0.1990 \\
\hline \multicolumn{9}{|l|}{ All training years } \\
\hline Number of fellows ( $n$ ) & 281 & 273 & & & 289 & 287 & & \\
\hline No. of procedures & 5523 & 13480 & $\begin{array}{l}59.03 \\
(58.2-59.86)\end{array}$ & & 19822 & 20113 & $1.45(1.29-1.62)$ & \\
\hline Mean procedures & $19.65 \pm 20.06$ & $49.38 \pm 38.38$ & & $<0.0001$ & $68.59 \pm 54.16$ & $70.08 \pm 53.63$ & & 0.7402 \\
\hline
\end{tabular}

grams, no substitute has yet been implemented for procedural volume, expertise, and training.

This current multi-institution study is the first attempt to objectively evaluate the impact of COVID-19 on endoscopic procedures and gastroenterology fellowship training in the United States. Furthermore, this study provides historical data to compare the initial, and more current impact to evaluate programs' ability to adapt training to the current pandemic. Based on the results of this multicenter study, there was a significant reduction in procedure volume during the initial stages of the COVID-19 pandemic, with the number of upper endoscopies and colonoscopies reduced by $48.75 \%$ and $59.03 \%$, respectively. Reassuringly, however, adaptive mechanisms (including relative ease of pre-procedural COVID-19 testing and availability of adequate personal protective equipment) have transformed the structure of current training with an increase in total number of endoscopic procedures, approaching a number similar to our 2019 historical cohort.

Procedure volume is a critical component of gastroenterology fellowship and training. Studies have suggested minimum thresholds ranging between 250 and 500 colonoscopies and around 250 upper endoscopies to achieve competence [10, 12,16-19]. The 2017 American Society of Gastroenterological Endoscopy (ASGE) guidelines, which is the standard for ACGMEaccredited gastroenterology fellowship programs, recommend that trainees perform a minimum of 130 upper endoscopies and 275 colonoscopies prior to assessment for competency [20]. Although these thresholds do not guarantee competence and ASGE places emphasis on shifting from a volume-based approach to assess competency towards more well-defined performance metrics, reduction in endoscopy volume is important as studies have demonstrated improved metrics such as cecal intubation rate, adenoma detection rate and polyp detection rate with higher volumes $[11,12,21]$. Based upon the results of this study, gastroenterology fellows appear to achieve these recommendations, even despite the COVID-19 pandemic. However, given that the pandemic has already impacted 10 months of a 36-month training program and is expected to continue for the foreseeable future, valid concerns have been raised [22]. Keswani et al proposed a phased approach to restarting training with implementation of newer educational models including an increase in online and simulated training [4]. As such, future investment by fellows, program leadership, and industry, into simulation training models may be required to supplement more traditional approaches. However, while these models may assist in training, though are unlikely to be a complete substitute for real-world procedures on live patients.

Ultimately, the results of this study suggest that although the pandemic is ongoing, procedure volume was effectively decreased for only a short period of time during the initial response and that adaptive measures have resulted in a return to near-normal volume and should likely not impact quality of 
endoscopy training for gastroenterology fellows. It is also imperative to note that although endoscopic volumes are important, competence cannot be based solely on procedure numbers and other factors including quality of training in those procedures need to be taken into account. This is, however, beyond the scope of this study.

Although there was no significant change in the total procedure volume, we found a shift of procedures towards third-year fellows during SP2. There was a decrease of $9.42 \%$ and $11.67 \%$ in the number of procedures performed by fellows in training years 1 and 2, respectively, in SP2 compared to HP2. During the same time, a non-significant increase of $15.84 \%$ was seen in procedures performed by fellows in training year 3 . We speculate that this may be due to a variety of subjective factors, including efforts to protect fellows in training years 1 and 2 by senior third-year fellows, faculty preferences to involve third-year trainees given experience and efficiency to avoid longer aerosol generating procedures, or a drive from senior trainees to get more experience prior to venturing out into practice. Even though we noticed this interesting trend, these differences were not significant when compared to HP2 for individual training year, and it should not impact the fellows in training years 1 and 2 in the long run as they have approximately 30 and 18 months of training ahead of them, respectively.

It is important to acknowledge this study is not without limitations. First, given the retrospective nature of the study, it is possible unmeasured confounders (i.e., specific fellow interest or other external non-COVID-19 factors) may have impacted the number of procedures during the predetermined time periods. In addition, given the heterogeneous nature of reporting institutions and main outcomes of the manuscript, specific data regarding possible fellow-specific outcomes, such as sex or race/ethnicity inequities, were not evaluated. Given that we had 23 centers participating in the study with different EMRs, we could not obtain additional data in a reliable way regarding the setting (inpatient vs. outpatient), indication, and urgency of the performed procedures. However, earlier during the pandemic, we audited the trends in upper gastrointestinal bleeding at the primary study site and found no trend in the absolute number of inpatients with hemodynamically unstable gastroenterology bleeding, esophagogastroduodenoscopies (EGDs) performed in the Intensive Care Unit or the number of inpatients undergoing EGD for variceal bleeding [14]. Further, this study was limited in its ability to evaluate specific measures taken by programs during the COVID-19 pandemic; however, it provides a barometer of objective evidence to demonstrate trends that are likely reflected across the country. Furthermore, for a few programs, data from all training sites could not be included for logistical reasons. However, given a typically consistent rotation schedule across the years, we do not expect this to be a major confounding factor.

Despite these limitations, this study possesses several strengths. Most importantly, this study included data from 23 training programs across the United States, reflecting approximately $11.3 \%$ of a total of 203 programs, encompassing $17.8 \%$ of an estimated 1,598 active trainees [23]. Furthermore, this study uniformly assessed the EMR or EERS reporting data, pro- viding an accurate objective measure of procedure volume instead of subjective data collected from anonymous surveys. Finally, this study had a unique ability to objectively measure procedure volume at two distinct time points during the COVID-19 pandemic - an early response during SP1, as well as an adaptive response during SP2.

\section{Conclusions}

In conclusion, there was a significant reduction in procedure volume among gastroenterology fellowship trainees during the initial stages of the COVID-19 pandemic. However, adaptive mechanisms have resulted in a return of procedure volume to baseline without ongoing impact on endoscopy training.

\section{Competing interests}

The authors declare that they have no conflict of interest.

\section{References}

[1] Cucinotta D, Vanelli M. WHO declares COVID-19 a pandemic. Acta Biomed 2020; 91: 157-160

[2] Lucey CR, Johnston SC. The transformational effects of COVID-19 on medical education. JAMA 2020; 324: 1033-1034

[3] Woolliscroft JO. Innovation in Response to the COVID-19 Pandemic Crisis. Acad Med 2020; 95: 1140-1142

[4] Keswani RN, Sethi A, Repici A et al. How to maximize trainee education during the Coronavirus disease-2019 pandemic: perspectives from around the world. Gastroenterology 2020; 159: 26-29

[5] Mallepally N, Bilal M, Hernandez-Barco YG et al. The new virtual reality: how COVID-19 will affect the gastroenterology and hepatology fellowship match. Dig Dis Sci 2020; 65: 2164-2168

[6] Shah R, Satyavada S, Ismail M et al. COVID-19 pandemic through the lens of a gastroenterology fellow: looking for the silver lining. Gastrointest Endosc 2020; 92: 394-398

[7] Imperatore N, Rispo A, Lombardi G. The price of being a doctor during the COVID-19 outbreak. Gut 2020; 69: 1544-1545

[8] Nasca TJ. ACGME response to the Coronavirus (COVID-19) Accreditation Council for Graduate Medical Education. ACGME response to the Coronavirus (COVID-19). https://acgme.org/Newsroom/NewsroomDetails/ArticleID/10111/ACGME-Response-to-the-Coronavirus-COVID-19/

[9] Rajendran A, Thomas-Gibson S, Bassett P et al. Lower gastrointestinal polypectomy competencies in the United Kingdom: a retrospective analysis of Directly Observed Polypectomy Skills (DOPyS). Endoscopy 2020: doi:10.1055/a-1234-8233

[10] Patwardhan VR, Feuerstein JD, Sengupta N et al. Fellowship colonoscopy training and preparedness for independent gastroenterology practice. J Clin Gastroenterol 2016; 50: 45-51

[11] Qayed E, Vora R, Levy S et al. Colonoscopy procedural volume increases adenoma and polyp detection rates in gastroenterologytrainees. World J Gastrointest Endosc 2017; 9: 540-551

[12] Ward ST, Mohammed MA, Walt R et al. An analysis of the learning curve to achieve competency at colonoscopy using the JETS database. Gut 2014; 63: 1746-1754

[13] Clarke K, Bilal M, Sanchez-Luna SA et al. Impact of COVID-19 pandemic on training: global perceptions of gastroenterology and hepa- 
tology fellows in the USA. Dig Dis Sci 2020: doi:10.1007/s10620-02006655-y

[14] Sobani ZA, Paleti S, Khalid S et al. Trends in upper gastrointestinal bleeding during the COVID-19 pandemic. Ann Gastroenterol 2020; 33: $543-544$

[15] Pawlak KM, Kral J, Khan R et al. Impact of COVID-19 on endoscopy trainees: an international survey. Gastrointest Endosc 2020; 92: 925935

[16] Miller AT, Sedlack RE. Competency in esophagogastroduodenoscopy: a validated tool for assessment and generalizable benchmarks for gastroenterology fellows. Gastrointest Endosc 2019; 90: 613-620. e611

[17] Spier BJ, Benson M, Pfau PR et al. Colonoscopy training in gastroenterology fellowships: determining competence. Gastrointest Endosc 2010; 71: 319-324
[18] Sedlack RE. Training to competency in colonoscopy: assessing and defining competency standards. Gastrointest Endosc 2011; 74: 355366.e351-352

[19] Sedlack RE, Coyle W]. Assessment of competency in endoscopy: establishing and validating generalizable competency benchmarks for colonoscopy. Gastrointest Endosc 2016; 83: 516-523.e511

[20] Faulx AL, Lightdale JR, Acosta RD et al. Guidelines for privileging, credentialing, and proctoring to perform gastroenterology endoscopy. Gastrointest Endosc 2017; 85: 273-281

[21] Sedlack RE, Coyle W], Obstein KL et al. ASGE's assessment of competency in endoscopy evaluation tools for colonoscopy and EGD. Gastrointest Endosc 2014; 79: 1-7

[22] Kissler SM, Tedijanto C, Goldstein E et al. Projecting the transmission dynamics of SARS-CoV-2 through the postpandemic period. Science 2020; 368: 860-868

[23] National Resident Matching Program. Fellowship Match Data and Reports. https://www.nrmp.org/fellowship-match-data/ 